\title{
EFEKTIVITAS PENGGUNAAN POROGAPIT CARD DALAM PEMAHAMAN PENYELESAIAN SOAL PEMBAGIAN DAN MOTIVASI BELAJAR SISWA DI TINGKAT SEKOLAH DASAR
}

\author{
Rio Febrianto Arifendi ${ }^{1}$, Nathasa Pramudita Irianti $^{2}$ \\ ${ }^{1,2}$ Universitas Tribhuwana Tunggadewi \\ rioarifendi@gmail.com ${ }^{1}$, nathasa1990@gmail.com ${ }^{2}$
}

Received 10 May 2020; revised 30 May 2020; accepted 12 June 2020.

\begin{abstract}
ABSTRAK
Tujuan dari penelitian ini adalah untuk mengetahui efektivitas penggunaan Porogapit Card untuk meningkatkan motivasi dan pemahaman siswa dalam menyelesaikan soal pembagian selama proses pembelajaran. Metode yang digunakan adalah Penelitian dan Pengembangan $(\mathrm{R} \& \mathrm{D})$, terbatas hingga tahap implementasi dan menggunakan metode kuasi eksperimen dengan satu kelompok pretest-posttest. Instrumen motivasi adalah kuesioner yang dimodifikasi oleh Keller dengan model ARCS, terdiri dari 4 aspek termasuk perhatian, relevansi, kepercayaan diri, dan kepuasan. Populasi adalah semua siswa dari kelas 5 SDN 1 Sidorejo, Pakis. Posttest diadakan untuk mengetahui motivasi dan pemahaman siswa dalam menyelesaikan soal pembagian dengan menggunakan Porogapit Card. Data dikumpulkan dari angket motivasi dan tes. Setelah menggunakan Porogapit Card, terdapat 14 siswa dengan kriteria motivasi tinggi $(71,91 \leq \mathrm{x}<86)$, 21 siswa dengan kriteria motivasi menengah $(57,82 \leq \mathrm{x}<71,91)$, dan 3 siswa dengan kriteria motivasi rendah $(43,74 \geq \mathrm{x})$, dan $84,2 \%$ siswa lulus dalam menyelesaikan soal pembagian. Berdasarkan analisis data, Porogapit Card layak digunakan untuk meningkatkan motivasi dan pemahaman belajar siswa.
\end{abstract}

Kata kunci: efektivitas, Porogapit Card, pemahaman, motivasi belajar

\begin{abstract}
The purpose of this study was to determine the effectiveness of using Porogapit Cards to increase students' motivation and understanding in solving division problems during the learning process. The method used is Research and Development (R\&D), limited to the implementation phase and using a quasi-experimental method with one group pretest-posttest. The motivation instrument is a questionnaire modified by Keller with the ARCS model, consisting of 4 aspects including attention, relevance, self-confidence, and satisfaction. The population is all students from grade 5 SDN 1 Sidorejo, Pakis. Posttest was held to find out the motivation and understanding of students in solving the problem of division by using Porogapit Cards. Data was collected from motivation and test questionnaires. After using the Porogapit Card, there were 14 students with high motivation criteria $(71.91 \leq \mathrm{x}<86), 21$ students with medium motivation criteria $(57.82<\mathrm{x}<71.91), 3$ students with low motivation criteria $(43.74 \geq \mathrm{x})$, and $84.2 \%$ of
\end{abstract}


students who graduated in solving the division problem. Based on data analysis, Porogapit Card is appropriate to be used to increase students' motivation and understanding of learning.

Keywords: effectiveness, Porogapit Card, understanding, learning motivation

\section{PENDAHULUAN}

Tahun-tahun pendidikan dasar merupakan menjadi penting karena merupakan waktu dimana peserta didik memperoleh banyak pengetahuan akademik dasar dan keterampilan sosial langsung dari sekolah. Namun salah satu subjek yang menjadi mata pelajaran yang kurang diminati adalah matematika sebagai salah satu subjek pelajaran yang sulit. Berdasarkan hasil survey tahun 2016 dari 789 peserta didik tingkat sekolah dasar, 62,6\% (494 responden) menyatakan bahwa matematika lebih sulit jika dibandingkan dengan IPA dan IPS, padahal 50,4\% (398 responden) juga ikut menyatakan bahwa matematika sangat penting untuk dipelajari (Dundar, 2014). Pentingnya pembelajaran matematika ini menyebabkan para pendidik harus mencari cara memudahkan pemahaman peserta didik agar mudah dalam menggunakan operasi hitung dalam kehidupan seharihari. Setidaknya mampu menguasai dan menggunakan konsep hitung dasar yang melibatkan penjumlahan, pengurangan, perkalian dan pembagian dengan baik, agar sesuai dengan salah satu tujuan mata pelajaran matematika yaitu peserta didik memiliki kemampuan dalam memahami, menjelaskan keterkaitan dan mengaplikasikan konsep atau algoritma, dengan luwes, akurat, efisien, sekaligus tepat dalam pemecahan masalah; (Setyono, 2007; BSNP, 2006).

Salah satu sekolah yang beberapa peserta didiknya mengalami kesulitan dalam menguasai konsep hitung dasar pembagian adalah SDN 1 Sidorejo, Pakis, Malang. Berdasarkan hasil observasi di kelas 5, ternyata masih banyak peserta didik yang kesulitan dalam beberapa topik yang diajarkan oleh guru, terutama pada materi soal pembagian. Penyebab kesulitan itu dikarenakan ketidakpahaman terhadap konsep, kesalahan dalam memahami masalah, dan kesulitan dalam proses perhitungan (Arifendi \& Wijaya, 2018). Terlihat beberapa peserta didik yang tidak banyak ikut berpartisipasi dalam proses belajar, mengantuk, tidak fokus, lebih suka mengganggu teman disebelahnya, hingga tidak mengerjakan soal pembagian sama sekali karena tidak paham dengan cara mengerjakannya. Hal ini menunjukkan bahwa motivasi dan pemahaman siswa pada soal pembagian 
masih rendah. Padahal Camos \& Baumer (2015) menyatakan bahwa pemahaman pada konsep pembagian ini sangat penting dimana anak yang lebih muda (3-6 tahun) harus sudah dikenalkan pada pembagian 1-2 digit sederhana sehingga terus mengeksplorasi kemampuan kognitifnya dengan pembagian digit yang lebih banyak. Sehingga walaupun pembagian sering dianggap sebagai operasi aritmatika sederhana yang paling sulit, diperlukan penyelesaian soal pembagian melalui beberapa metode atau cara dalam mengajarkan operasi dalam pembagian, salah satunya adalah contoh metode operasi pembagian tradisional adalah dengan menggunakan metode porogapit. Porogapit adalah sebuah metode pembagian bersusun dengan membuat garis pengapit antara bilangan yang dibagi dan bilangan pembaginya. Diambil dari bahasa jawa yaitu Poro dan Gapit yang memiliki arti 'bagi (membagi)' dan 'pengapit'. Secara maknawi Porogapit bisa diartikan menjadi membagi sebuah bilangan dengan meletakkan garis pengapit diantara bilangan pembagi dan yang dibagi (Abdurrahman, 2010).

Selain observasi tersebut, wawancara juga dilakukan oleh guru dimana peserta didik umumnya mulai kesulitan jika soal pembagian mulai mencapai 3 digit, hingga ratusan walaupun sudah menggunakan teknik porogapit. Siswa banyak yang melakukan kesalahan dalam menyelesaikan soal pembagian menggunakan porogapit, siswa selalu lupa dan memulai teknik porogapit dari akhir digit bukan dari awal digit sehingga banyak kesalahan dari perhitungan. Hal ini dibuktikan dari hasil latihan soal siswa yang menunjukkan hanya 31,57\% (12 siswa) dan menurun pada latihan kedua pada soal pembagian 3 digit angka dimana hanya 21,05\% (8 siswa) yang memiliki nilai di atas KKM 70.

Berdasarkan paparan tersebut, perlu adanya inovasi dari teknik porogapit yang telah diberikan oleh guru kepada siswa khususnya kelas 5 SD dalam pemahaman penyelesaian soal pembagian dengan metode porogapit, salah satunya melalui Porogapit Card. Porogapit Card merupakan kartu pembagian dengan teknik porogapit yang telah diberi warna merah, hijau, kuning dan biru. Setiap kolom warna dapat dituliskan 1 hingga 4 digit angka. Kolom pertama yang harus dibagi adalah kolom warna merah dan hijau hingga seterusnya hingga kolom berwarna biru. Pemberian warna ini diharapkan agar dapat memudahkan siswa SD untuk mengingat teknik pembagian sederhana porogapit. Sehingga penelitian ini bertujuan untuk mengetahui efektivitas penggunaan Porogapit Card dalam 
pemahaman penyelesaian soal pembagian tingkat sekolah dasar khususnya pada siswa kelas 5 di SDN 1 Sidorejo, Pakis.

\section{METODE PENELITIAN}

Penelitian ini adalah Penelitian dan Pengembangan (R\&D), menggunakan ADDIE dari Dick and Carey untuk Analisis, Desain, Pengembangan dan terbatas pada Implementasi. Kegiatan yang dilakukan dalam penelitian ini adalah menemukan produk yang perlu dikembangkan, menentukan desain produk, uji validitas produk oleh para ahli, sampai dengan tahap pengujian untuk membuktikan supremasi produk yang akan dibahas lebih lanjut dalam penelitian ini. Metode yang digunakan adalah eksperimen semu dengan desain satu kelompok pretest-posttest. Adapun sampel yang digunakan dari seluruh populasi siswa kelas 5 SDN 1 Sidorejo, Pakis yang berjumlah 38 siswa. Bentuk pengembangan produk adalah kartu porogapit dengan 4 warna berbeda (merah, kuning, hijau, biru) dengan setiap kolom warnanya berisi 1 digit. Perhitungan selalu diawali dengan kolom warna merah dan kuning, kemudian dilanjutkan hijau dan biru jika pembagian hingga 4 digit yang diberikan untuk mengetahui pengaruhnya terhadap motivasi dan pemahaman siswa dalam menyelesaikan soal pembagian. Sebagai data tambahan, motivasi siswa akan berkorelasi dengan hasil belajar siswa.

\section{HASIL PENELITIAN DAN PEMBAHASAN}

Dalam penelitian ini langkah-langkah yang digunakan merupakan langkah dari metode ADDIE yang dibatasi hanya pada implementasi (implementation steps) yang dilakukan di SDN 1 Sidorejo, Pakis. Pada tahap awal yaitu tahap analisis, masalah yang terindentifikasi adalah siswa masih kurang memahami cara kerja dari porogapit dalam menyelesaikan soal pembagian, umumnya siswa lupa dan salah dalam mengaplikasikan sehingga dibutuhkan inovasi agar teknik porogapit ini dapat diterapkan oleh siswa dengan benar. Pada tahap desain, dilakukan pembuatan konsep atau framework untuk mengatasi masalah tersebut yaitu melalui Porogapit Card atau kartu porogapit dengan warna menarik untuk membantu pemahaman siswa dalam soal pembagian. Pada tahap pengembangan, yaitu mulai penerapan framework ke wujud nyata yang divalidasi oleh ahli pada aspek media dan materi. Pada aspek materi, kesesuaian dengan konten bernilai 
4,00; dan kesesuaian representasi bernilai 3,83, kemudian pada aspek media, kesesuaian grafik media dengan konten bernilai 4,25. Berarti seluruh penilaian pada aspek materi dan media adalah sesuai dan dapat digunakan. Setelah pembelajaran dan dilakukan tes pemahaman dalam menggunakan Porogapit Card, data nilai siswa mulai dikumpulkan dan dideskripsikan menggunakan gainscore, yang disajikan Pada Tabel 1.

Tabel 1. Normalized Gain Score (N-Gain Score) Pemahaman Soal Pembagian Siswa Menggunakan Porogapit Card

\begin{tabular}{ccccc}
\hline \multirow{2}{*}{ Deskripsi } & \multicolumn{2}{c}{ Motivasi Siswa } & \multicolumn{2}{c}{ Pemahaman Siswa } \\
& Pretest & Posttest & Pretest & Posttest \\
\hline Sample & 38 & 38 & 38 & 38 \\
High Score & 110 & 128 & 60 & 90 \\
Low Score & 105 & 137 & 30 & 50 \\
Total Value & 2805,92 & 3681,8 & 1790 & 2720 \\
Average Value & 56,11 & 73,63 & 47,10 & 71,57 \\
N-Gain Score & \multicolumn{2}{c}{0,39} & \multicolumn{2}{c}{0,45} \\
Category & Moderate & \multicolumn{2}{c}{ moderate } \\
Improve $(\%)$ & \multicolumn{2}{c}{51,2} & \multicolumn{2}{c}{} \\
\hline
\end{tabular}

Berdasarkan hasil $\mathrm{N}$-Gain pada Tabel 1, setelah menggunakan Porogapit Card aspek motivasi dan hasil belajar siswa mencapai skor 0,39 dan 0,45 dengan kategori sedang, dengan persentase peningkatan motivasi siswa adalah 3,12\% , dan $51,9 \%$ dalam pemahaman soal pembagian. Itu berarti bahwa efektivitas Porogapit Card berada di tingkat menengah untuk meningkatkan motivasi dan hasil pemahaman belajar siswa. Hasil skor rata-rata dalam motivasi dan hasil pemahaman belajar siswa akan ditampilkan dalam Gambar 1 .

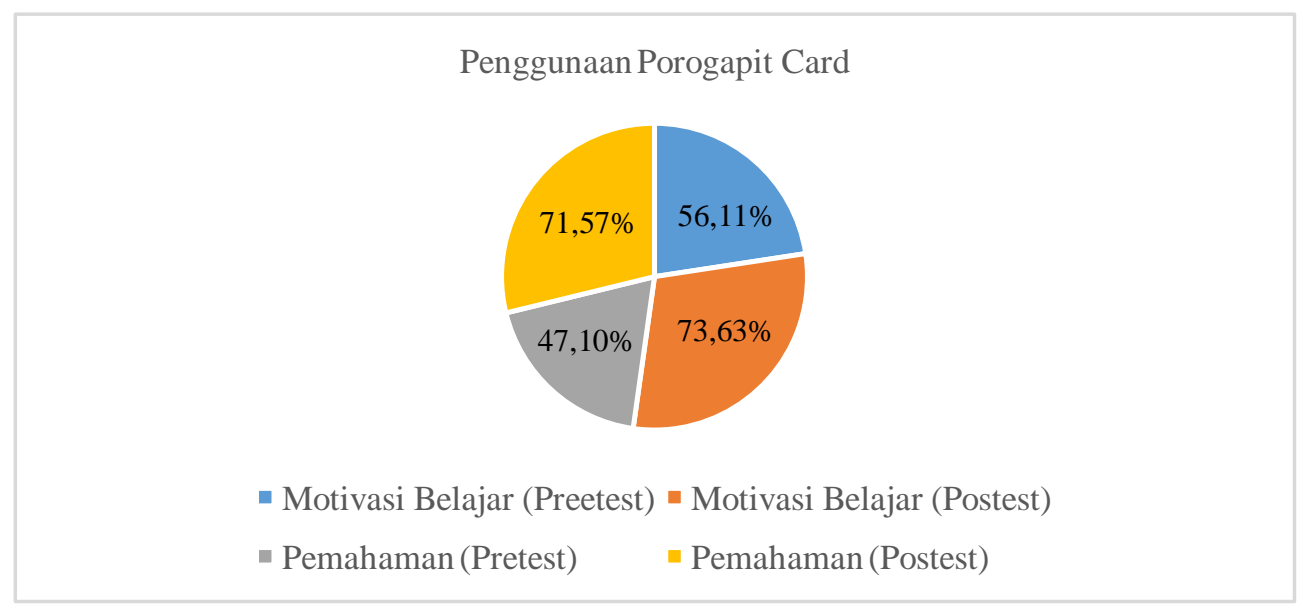

Gambar 1. Diagram Nilai Rata-Rata Pretest-Posttest Motivasi dan Pemahaman Belajar Siswa 
Gambar 1 menunjukkan tentang skor rata-rata antara pretest dan posttest dalam motivasi dan hasil pemahaman belajar siswa. Itu menunjukkan bahwa setelah menggunakan Porogapit Card, selisih motivasi siswa antara pretest dan posttest sebesar 17,52, sedangkan selisih hasil belajar siswa sebesar 24,47. Dalam aspek motivasi, terdapat $44,73 \%$ atau 19 siswa dalam kategori sangat rendah, 44,73\% atau 17 siswa dalam kategori sedang, dan 5,2\% atau 2 siswa dalam kategori tinggi berdasarkan hasil pretest setelah dilakukan pembelajaran seperti biasanya. Sementara setelah pembelajaran menggunakan Porogapit Card, hasil posttest menunjukkan ada 7,89\% atau 3 siswa dalam kategori rendah, 55,26\% atau 21 siswa dalam kategori sedang, dan 36,84\% atau 14 siswa dalam kategori tinggi. Dalam aspek hasil pemahaman siswa pada penyelesaian soal pembagian setelah menggunakan Porogapit Card, diperoleh $15,7 \%$ siswa tidak lulus, sementara ada $84,2 \%$ siswa yang lulus dalam pengerjaan soal pembagian di kelas 5 .

Sebelum melakukan tes statistik pada motivasi siswa, uji normalitas dilakukan. Dengan menggunakan tes liliefors diperoleh skor 0,101>0,05 dalam pretest, dan 0,113>0,05 pada posttest. Hal tersebut berarti semua data dalam motivasi siswa memiliki distribusi normal. Kemudian uji-t berpasangan dilakukan pada Tabel 2 dan 3.

Tabel 2. Paired Sample Correlation Motivasi Siswa

\begin{tabular}{llccc}
\hline & N & Correlation & Sig. \\
\hline Pair 1 & Pretest \& Posttest & 38 & .362 & .001 \\
\hline
\end{tabular}

Menurut korelasi sampel berpasangan pada Tabel 2, menunjukkan ada korelasi yang signifikan antara pretest dan posttest, sebelum dan sesudah menggunakan Porogapit Card dengan signifikansi 0,001<0,05 dan nilai korelasi 0,362 . Berarti ada korelasi positif antara pengukuran motivasi pada pre-test dan pada post-test yang menunjukkan keselarasan data pretest dan posttest.

Tabel 3. Paired Sample Test Motivasi Siswa

\begin{tabular}{|c|c|c|c|c|c|c|c|c|c|}
\hline & & mean & $\begin{array}{c}\text { Std. } \\
\text { Deviation }\end{array}$ & $\begin{array}{l}\text { Std. } \\
\text { Error }\end{array}$ & $\begin{array}{l}95 \% \text { Conf } \\
\text { Interval of D }\end{array}$ & $\begin{array}{l}\text { dence } \\
\text { fference }\end{array}$ & $\mathrm{T}$ & df & $\begin{array}{l}\text { Sig. } \\
(2- \\
\text { tailed) }\end{array}$ \\
\hline & & & & Mean & Upper & Lower & & & \\
\hline Pair 1 & $\begin{array}{c}\text { Pretest- } \\
\text { Posttet }\end{array}$ & -17.51760 & 11.47851 & 1.62331 & -20.77976 & -14.25544 & -10.131 & 37 & .000 \\
\hline
\end{tabular}


Menurut uji sampel berpasangan pada Tabel 3 menunjukkan bahwa signifikansinya adalah $0,000<0,05$ yang berarti ada perbedaan nilai rata-rata motivasi siswa antara pretest dan posttest. Hal ini juga dibuktikan dengan skor $\mathrm{t}$ jika dibandingkan dengan skor t tabel, 10,131> 2,00958 yang juga berarti ada dampak menggunakan Porogapit Card dalam meningkatkan motivasi siswa.

Kemudian dilanjutkan dengan tes statistik pada hasil belajar siswa tetapi sebelum melakukan hal yang sama dengan motivasi siswa, tes normalitas perlu dilakukan. Dengan tes liliefors diperoleh skor pretest $0,111>0,05$ dan 0,087>0,05 pada posttest. Hal tersebut berarti semua data dalam motivasi siswa memiliki distribusi normal. Kemudian uji-t berpasangan dilakukan pada Tabel 4 dan 5

Tabel 4. Paired Sample Correlation Pemahaman Belajar Siswa

\begin{tabular}{ccccc}
\hline & N & Correlation & Sig. \\
\hline Pair 1 & Pretest \& Posttest & 50 & .372 & .020 \\
\hline
\end{tabular}

Menurut korelasi sampel berpasangan pada Tabel 4 menunjukkan bahwa ada korelasi yang signifikan antara pretest dan posttest, sebelum dan sesudah menggunakan Porogapit Card dengan signifikansi 0,020<0,05 dan nilai korelasi 0,372. Berarti ada korelasi positif antara pengukuran hasil pemahaman belajar siswa pada pretest dan pada posttest yang menunjukkan keselarasan data pretest dan posttest.

Tabel 5. Paired Sample Test Pemahaman Belajar Siswa

\begin{tabular}{|c|c|c|c|c|c|c|c|c|c|}
\hline & & \multirow[t]{2}{*}{ mean } & \multirow{2}{*}{$\begin{array}{c}\text { Std. } \\
\text { Deviatio } \\
\text { n }\end{array}$} & \multirow{2}{*}{$\begin{array}{l}\text { Std. } \\
\text { Error } \\
\text { Mean }\end{array}$} & \multicolumn{2}{|c|}{$\begin{array}{l}95 \% \text { Confidence } \\
\text { Interval of Difference }\end{array}$} & \multirow[t]{2}{*}{$\mathrm{t}$} & \multirow[t]{2}{*}{ df } & \multirow[t]{2}{*}{$\begin{array}{l}\text { Sig. (2- } \\
\text { tailed) }\end{array}$} \\
\hline & & & & & Upper & Lower & & & \\
\hline $\begin{array}{c}\text { Pair } \\
1\end{array}$ & $\begin{array}{l}\text { Pretest- } \\
\text { Posttet }\end{array}$ & -22.64820 & 13.59562 & 1.92271 & -26.51203 & -18.78437 & -11.779 & 37 & .000 \\
\hline
\end{tabular}

Menurut uji sampel berpasangan pada Tabel 5 menunjukkan bahwa signifikansinya adalah $0,000<0,05$ yang berarti ada perbedaan nilai rata-rata hasil pemahaman belajar siswa antara pretest dan posttest. Hal ini juga terbukti dengan skor $\mathrm{t}$ jika dibandingkan dengan skor t tabel, 11.779> 2.00958 yang juga berarti ada dampak menggunakan Porogapit Card dalam meningkatkan hasil pemahaman belajar siswa.

Penerapan Porogapit Card pada kelas 5 ternyata dapat memudahkan siswa dalam menyelesaikan soal pembagian dan juga dapat meningkatkan motivasi. Hal 
ini dikarenakan Porogapit Card dapat mengatasi beberapa masalah seperti kesulitan dalam penyelesaian menggunakan teknik biasa, yaitu melalui bantuan warna-warna yang menarik. Ketika guru hanya memberikan penjelasan bagaimana cara mengerjakan progapit dengan cara sederhana, maka hanya akan masuk ke dalam prior memoryatau memori jangka pendek yang mudah sekali untuk dilupakan, sedangkan Porogapit Card dapat memberikan ilustrasi yang menarik dan interaktif dengan ilustrasi warna-warni sehingga siswa dapat mempelajari hal-hal nyata yang terjadi di sekitar dan mengetahui langsung tentang manfaatnya. Meskipun soal pembagian dapat menjadi sulit bagi siswa, tetapi melalui representasi penuh warna dan berdasarkan aktivitas nyata yang terjadi di sekitar siswa dapat membangun dan memicu perhatian siswa tingkat SD. Hal tersebut dikarenakan siswa tingkat SD lebih menyukai visual yang menarik untuk disimpan dalam memori jangka panjang mereka (Hoque, 2018; Keller dkk, 2009; Liaw dkk, 2007). Porogapit Card ini dapat membawa perasaan menyenangkan, dan keterlibatan siswa, sehingga dapat dengan mudah memfasilitasi pemahaman siswa dan keterlibatan ini tentu saja dapat meningkatkan kepercayaan diri dan pemahaman mereka, serta dapat memberikan pembelajaran aktif dan mandiri yang dapat meningkatkan kepuasan para siswa di kelas (Dohaney dkk, 2017; Keller dkk, 2009; Nurhayati dkk, 2017).

Motivasi siswa berkontribusi dalam proses pembelajaran karena juga berkaitan dengan hasil belajar siswa salah satunya juga berkaitan pada pemahan siswa. Wigfield dan Cambria (2010), mengatakan bahwa komponen afektif dan kognitif berhubungan dengan keterlibatan aktivitas peserta didik. Hubungan yang kuat antara motivasi dan pemahaman dalam belajar dapat menjadi kombinasi yang terus meningkatkan partisipasi siswa sehingga dapat meningkatkan kinerja akademik yang lebih baik (Alavi \& Leidner, 2001; Benbunan-Fich \& Hiltz, 2003). Data korelasi ditunjukkan dalam Tabel 6.

Tabel 6. Analisis Korelasi antara Motivasi dan Pemahaman Belajar Siswa

\begin{tabular}{cccc}
\hline & Students' & $\begin{array}{c}\text { Students' Learning } \\
\text { Ootivation }\end{array}$ & Outcomes \\
\hline Motivasi & Pearson & 1 & .153 \\
Belajar & Correlation & & .012 \\
& Sig. (2-tailed) & & 38 \\
Pemahaman & N & 38 & 1 \\
Siswa & Pearson & .153 & \\
\hline
\end{tabular}


Sig. (2-tailed) $\quad .012$

$\mathrm{N} \quad 38 \quad 38$

Analisis korelasi pada Tabel 6 menunjukkan korelasi signifikan pada tingkat signifikan 0,012 (2-tailed). Jumlah korelasi Pearson adalah 0,153, menunjukkan tentang tingkat korelasi antara motivasi belajar siswa dan pemahaman konseptual siswa di kelas eksperimen berada dalam kategori lemah. Hal ini dikarenakan penggunaan Porogapit Card dalam penelitian tidak maksimal hanya diukur selama beberapa pertemuan. Dan untuk hasil terbaik dalam motivasi siswa dan hasil belajar membutuhkan waktu yang cukup lama untuk memunculkan pentingnya belajar dalam kehidupan siswa (Mitcell, 1993), tetapi korelasi positif menunjukkan bahwa ketika motivasi siswa meningkat maka hasil belajar siswa juga ditingkatkan.

\section{SIMPULAN}

Berdasarkan hasil penelitian ini, penerapan Porogapit Card dapat meningkatkan motivasi siswa dengan memenuhi semua indikator motivasi seperti perhatian, relevansi, kepercayaan diri, dan kepuasan. Peningkatan motivasi siswa juga berdampak pada hasil belajar siswa berdasarkan analisis korelasi dengan 84,2\% siswa telah lulus kelas setelah menggunakan Porogapit Card di kelas 5 SDN 1 Sidorejo, Pakis. Meskipun dalam kategori korelasi yang lemah, ini dapat dibantu dengan memaksimalkan penggunaan Porogapit Card dalam setiap proses pembelajaran.

\section{DAFTAR PUSTAKA}

Abdurrahman, M. (2010). Pendidikan bagi anak kesulitan belajar. Jakarta: Rineka Cipta.

Alavi, M., \& Leidner, D. E. (2001). Research commentary: technology-mediated learning - a call for greater depth and breadth of research. Information Systems Research, 12(1), 1-10. http://doi.org/10.1287/isre.12.1.1.9720.

Arifendi, R. F., \& Wijaya, E. M. S. (2018). Diagnosis Kesulitan Peserta Didik dan Upaya Pemberian Scaffolding dalam Menyelesaikan Masalah Geometri. Didaktis:Jurnal Pendidikan dan Ilmu Pengetahuan, 18(1), 1230 .

Benbunan-Fich, R., \& Hiltz, S. R. (2003). Mediators of the effectiveness of online courses. IEEE Transactions on Professional Communication, 46(4), 298312. http://doi.org/10.1109/tpc.2003.819639. 
BSNP. (2006). Permendiknas RI no. 22 tahun 2006 tentang standar isi untuk satuan pendidikan dasar dan menengah. Jakarta.

Camos, V., \& Baumer, J. (2015). Why is it so hard to solve long divisions for 10year-old children? International Journal of School and Cognitive Psychology, S2: 007. http://doi.org/10.4172/2469-9837.1000S2-007.

Dohaney J., Brogt E., Wilson T.M., Kennedy B. (2017). Using role-play to improve students' confidence and perceptions of communication in a simulated volcanic crisis. In: Fearnley C.J., Bird D.K., Haynes K., McGuire W.J., Jolly G. (eds) Observing the Volcano World. Advances in Volcanology (An Official Book Series of the International Association of Volcanology and Chemistry of the Earth's Interior IAVCEI, Barcelona, Spain). Springer, Cham. http://doi.org/10.1007/11157_2016_50.

Dündar, Ş., Güvendir, M.A., Kocabıyık, O.O., \& Papatga, E. (2014). Which elementary school subjects are the most likeable, most important, and the easiest? why?: a study of science and technology, mathematics, social studies, and Turkish. Educational Research and Reviews, 9(13), 417-428. http://doi.org/10.5897/ERR2014.1755.

Hoque, E. (2018). Memorization: a proven method of learning. International Journal of Applied Research, 22, 142-150.

Keller, J. M. (2009). The arcs model of motivational design. In: Motivational design for learning and performance. Boston: Springer. http://doi.org/10.1007/978-1-4419-1250-3_3.

Liaw, S.-S., Huang, H.-M., \& Chen, G.-D. (2007). Surveying instructor and learner attitudes toward e-learning. Computers \& Education, 49(4), 10661080. http://doi.org/10.1016/j.compedu.2006.01.001.

Nurhayati, N., Rosmaiyadi, R., \& Buyung, B. (2017). Efforts to improve student's self confidence using collaborative learning model. JPMI (Jurnal Pendidikan Matematika Indonesia), 2(2), 57-62. http://doi.org/10.26737/jpmi.v2i2.223.

Setyono, A. (2007). Mathemagic cara genius belajar matematika, Jakarta: Gramedia Pustaka Utama.

Wigfield, A., \& Cambria, J. (2010). Students' achievement values, goal orientations, and interest: definitions, development, and relations to achievement outcomes. Developmental Review, 30(1), 1-35. http://doi.org/10.1016/j.dr.2009.12.001. 